Session 2793

\title{
ESTIMATION OF LAMINAR BURNING VELOCITIES BY DIRECT DIGITAL PHOTOGRAPHY
}

\author{
J. Uske and R. Barat* \\ Chemical Engineering Department \\ New Jersey Institute of Technology \\ University Heights \\ Newark, NJ 07102
}

\begin{abstract}
By being a function of both transport (diffusion) and chemical reaction rates, the laminar burning velocity (LBV) of a gaseous fuel/oxidant mixture is a window to the complexities of combustion. Direct photography of the inner cone of a Bunsen flame remains a classical measurement technique for estimating LBVs. The availability and utility of the modern digital camera, together with the ease and power of digital photograph computer processing, greatly facilitate the determination of LBVs, especially for the undergraduate laboratory. In this work, the LBVs of hydrocarbon/air mixtures are estimated using direct digital photography. In addition, selected flames doped with ammonia are studied. The estimated precision of this technique illustrates the need for careful measurements.
\end{abstract}

\section{Introduction}

Undergraduate experiments on flame dynamics are rare since actual temperatures are very high, and rates are very fast. However, the most common flame in the laboratory can now be easily studied thanks to modern digital technology economically available to student laboratories.

Consider the Bunsen flame in Figure 1. The inner cone is referred to as the premixed region, while the outer region is the diffusion envelope. In a simple interpretation, the flame is stable on the burner because the cold gas velocity at the flame front matches the speed at which the flame propagates upstream (the burning velocity). In this idealized Bunsen flame configuration, the laminar burning velocity (LBV) can be defined as the component of the cold gas velocity passing normal to the flame front ${ }^{(1)}$ as given by:

$$
\mathrm{S}_{\mathrm{u}}=\overline{\mathrm{u}}_{\mathrm{g}} \sin (\theta / 2)
$$

where $\mathrm{S}_{\mathrm{u}}=$ laminar burning velocity, $\overline{\mathrm{u}}_{\mathrm{g}}=$ mean cold gas laminar velocity (gas volumetric flow rate $\div$ tube cross section), and $\theta=$ cone apex angle.

In real Bunsen flames, curvature at the apex makes Equation 1 problematic. Alternative formulations ${ }^{(2)}$ that avoid curvatures at the cone apex and base are useful, as 
well as indirect photographic methods such as shadowgraphy ${ }^{(3)}$. Most of the LBV literature data are based on Bunsen flame measurements ${ }^{(2)}$ of some type.

A simple thermal analysis of the flame front considers the propagation of a laminar combustion wave through a gaseous fuel/oxidant mixture. As described by Glassman $^{(4)}$, the LBV can be shown to be proportional to the square root of the product of the thermal diffusivity of the feed gas mixture $\left(a=k / \rho C_{p}\right)$ and an overall combustion reaction rate $(R)$ :

$$
S_{L} \propto[a R]^{0.5}
$$

where $\mathrm{k}=$ thermal conductivity, $\rho=$ mass density, and $\mathrm{C}_{\mathrm{p}}=$ mean heat capacity. Therefore, the LBV of a fuel/oxidant mixture indicates that both transport and chemical kinetic effects are important in a flame.

Barat $^{(5)}$ showed that Eq. 2 can be reformulated as:

$$
S_{L} \propto\left[\frac{a}{\tau_{\bar{B} 0}}\right]^{0.5}
$$

where $\tau_{\mathrm{BO}}=$ the space (residence) time at extinction (blowout) of a hypothetical perfectly stirred reactor (PSR) feeding the fuel/oxidant gas mixture. Such calculations can be performed for many simple fuel/oxidant feeds using detailed chemical reaction mechanisms available in the literature and the PSR program from Chemkin ${ }^{\circledR}{ }^{(6)}$. Using pure component $\mathrm{k}, \rho$, and $\mathrm{C}_{\mathrm{p}}$ values, a simple mole fraction-weighted a can be estimated.

Though very important in so many practical applications, combustion as a scientific phenomenon is often overlooked in the undergraduate laboratory. The Bunsen burner is considered merely as a heat source. However, students can easily be taught to view flames as a chemically reacting flow with implications beyond simply that of a heat source. For example, additives that lower flame speeds can result in products of incomplete combustion - a significant environmental issue affecting incineration.

In this paper, a relatively easy and economic way to bring flame dynamics into the undergraduate engineering laboratory is described. Direct digital photography of Bunsen flames is used to obtain LBVs of selected gaseous hydrocarbon/air flames, including several doped with ammonia gas. A modern digital camera of the type available in consumer electronics stores, together with a common digital photograph processing computer program, are used. A discussion of the precision of the technique is included.

\section{Experimental}

The layout is shown in Figure 2. Air and fuel gas flows are metered in carefully calibrated rotameters or mass flow controllers. A 90 micron porous metal in-line filter placed just before the burner tube acts as a flashback flame arrestor. The premixed gas feed flows through a ventless $0.79 \mathrm{~cm}$ ID or similarly sized stainless steel tube serving as the Bunsen burner. Based on cold gas velocities, our Bunsen tube Reynolds numbers are 900 - 1800 indicating laminar flow. Black metal walls on three sides shield the flame from most room air currents. 
A securely mounted Sony ${ }^{\circledR}$ model DSC-S50 "Cyber-shot" ${ }^{\circledR}$ digital chargecoupled-device (CCD) camera is positioned at least $20 \mathrm{~cm}$ from the tube. Because of the nature of the image processing (described below), it is important that the flame image also include the upper rim of the burner as well as the complete inner cone. The camera is usually operated in its automatic exposure mode, with two pictures of a given flame taken. Two successive, quality images of the same flame yield nearly identical results.

The digital images are stored on the memory stick of the camera as individual joint-photographic-experts-group (JPEG) files. The JPEG files are then transferred, via universal serial bus (USB) cable, from the camera to a personal computer. The JPEG image files are examined with Adobe ${ }^{\circledR}$ PhotoShop ${ }^{\circledR}$ or similar digital photo software. Though modifications such as background removal can be done, we have found that simple flame image magnification is all that is typically required. Occasionally, conversion of the image from color to black-and-white enhanced the contrast.

\section{Estimation of LBV}

Curvature at the apex and base of the inner "cone" of real Bunsen flames renders Eq. 1 impractical. A generalized approach ${ }^{(2)}$ sets the LBV as the ratio of the cold gas volumetric flow rate to the total lateral surface area of the cone. In order to avoid the curvatures, the area is restricted to a frustrum as shown in Figure 3. The frustrum can be drawn over as much of the cone as possible while avoiding curvature in the lateral sides. This typically results in use of about 3/4 of the total cone height. Considering only that portion of the total volumetric flow passing through the lateral surface area of the frustrum, Dery ${ }^{(2)}$ derived:

$$
\mathrm{S}_{\mathrm{u}}=2 \overline{\mathrm{u}}_{\mathrm{g}} \frac{\left(\mathrm{r}_{2}-\mathrm{r}_{1}\right)}{\mathrm{s}}\left[1-\frac{\left(\mathrm{r}_{2}^{2}+\mathrm{r}_{1}^{2}\right)}{2 \mathrm{R}^{2}}\right]
$$

where $r_{1}$ and $r_{2}=$ radii of the top and bottom of the frustrum, respectively, $s=$ slant height, and $\mathrm{R}=$ inside radius of the Bunsen tube. This "frustrum" method has been used successfully ${ }^{(7)}$, with a precision comparable to other optical methods ${ }^{(3)}$ for LBVs.

The key to the utility of the frustrum method as used in this study is that absolute dimensions are not needed for the image processing. Any magnification factor from original object (flame) to computer digital image cancels out in Eq. 4. Therefore, relative measurements of the required quantities $r_{1}, r_{2}, s$, and $R$ directly from the computer screen actually works. Our best results are obtained by drawing the trapezoid (frustrum projection) on the inside of the luminous flame front thickness of the digital image.

\section{Results and Discussion}

The LBVs for a given fuel/oxidant system are typically presented as functions of fuel equivalence ratio $\phi$ :

$$
\phi=(\text { fuel/air })_{\text {actual }} /(\text { fuel/air })_{\text {stoichiometric }}
$$


where "fuel" and "air" represent molar or volumetric rates. The $\phi$ is based on an overall stoichiometry where reactants yield the thermodynamically most stable products.

Premixed flames are "fuel-lean" $(\phi<1)$, "stoichiometric" $(\phi=1)$, or "fuel-rich" $(\phi>1)$.

\section{Methane/Air}

Figure 4 illustrates our experimental LBVs for atmospheric pressure methane $\left(\mathrm{CH}_{4}\right)$ /air Bunsen flames as a function of $\phi$. For the $\mathrm{CH}_{4}$ /air feeds, $\phi$ is based on:

$$
\mathrm{CH}_{4}+2 \mathrm{O}_{2}=\mathrm{CO}_{2}+2 \mathrm{H}_{2} \mathrm{O}
$$

resulting in a governing relation for the feed:

$$
\phi=9.524\left(\frac{F_{M}}{\mathrm{~A}}\right)
$$

where $\mathrm{F}_{\mathrm{M}}=\mathrm{CH}_{4}$ flow rate, and $\mathrm{A}=$ air flow rate. Typical Bunsen tube Reynolds numbers here are $\sim 900$.

Because of the intrinsic difficulties in obtaining accurate and consistent LBVs, our data are presented as points in comparison to the data of several researchers as presented elsewhere ${ }^{(1,2)}$. The precision of our results for the LBV and the $\phi$ scales are based on very conservative propagating error analyses. For example, we report an LBV $=42.1+/-10.6$ at $\phi=1.04+/-0.06$. The uncertainty in the LBV $(\sim 25 \%)$ is not unreasonable considering the variation in literature results. Our experience indicates that accurate and precise knowledge of the flow rates establishing $\phi$ is essential. In addition, care must be taken not to saturate the digital image due to flame brightness.

\section{Ethylene/Air}

In the next stage of experiments, ethylene $\left(\mathrm{C}_{2} \mathrm{H}_{4}\right)$ is the fuel. Due to its higher heat of formation, the unsaturated $\mathrm{C}_{2} \mathrm{H}_{4}$ burns at greater velocities, thus requiring higher total fuel+air flow rates to achieve stable Bunsen flames. The typical Reynolds numbers were $\sim 1800$. The overall stoichiometry:

$$
\mathrm{C}_{2} \mathrm{H}_{4}+3 \mathrm{O}_{2}=2 \mathrm{CO}_{2}+2 \mathrm{H}_{2} \mathrm{O}
$$

results in a $\phi$ formula of:

$$
\phi=14.29\left(\frac{\mathrm{F}_{\mathrm{E}}}{\mathrm{A}}\right)
$$

where $\mathrm{F}_{\mathrm{E}}=\mathrm{C}_{2} \mathrm{H}_{4}$ volumetric flow rate. Figure 5 presents experimental and literature LBVs for atmospheric pressure $\mathrm{C}_{2} \mathrm{H}_{4}$ /air Bunsen flames as a function of $\phi$. The peak LBV still occurs at $\phi \sim 1.1$, which is characteristic of most hydrocarbon fuels ${ }^{(1)}$. The peak LBV is 
$\sim$ twice that of $\mathrm{CH}_{4}$. Our results compare well to the literature, which also is subject to a range (not shown) similar to that seen for $\mathrm{CH}_{4} /$ air ${ }^{(3)}$.

\section{Methane/Ammonia/Air}

Introduction of ammonia $\left(\mathrm{NH}_{3}\right)$ gas into the $\mathrm{CH}_{4}$ /air feed results in the overall stoichiometry:

$$
\mathrm{CH}_{4}+r \mathrm{NH}_{3}+\left(\frac{3 r+8}{4}\right) \mathrm{O}_{2}=\mathrm{CO}_{2}+\left(\frac{3 r+4}{2}\right) \mathrm{H}_{2} \mathrm{O}+\left(\frac{r}{2}\right) \mathrm{N}_{2}
$$

resulting in the $\phi$ formula:

$$
\phi=1.19\left(\frac{F_{M}}{A}\right)(1+r)(3 r+8)
$$

where $r \equiv F_{A} / F_{M}$ and $\mathrm{F}_{\mathrm{A}}=\mathrm{NH}_{3}$ flow rate. Figure 6 presents experimental LBVs for atmospheric pressure $\mathrm{CH}_{4} / \mathrm{NH}_{3}$ /air Bunsen flames as a function of $\phi$ for $\mathrm{r}=0.25$. It is clear that, over the range of $\phi$ values tested, $\mathrm{NH}_{3}$ acts to lower the $\mathrm{CH}_{4} /$ air LBV.

Table 1 illustrates that a degree of flexibility exists in these experiments. Five different flames were tested at constant $\phi=1.25$ and $r=0.15$ by varying the total volumetric flow rate, and thus the cold gas velocity. The results are consistent. Borrowing the simple notion of Figure 1 and Eq. 1, at constant feed concentration and temperature, increasing the cold gas flow rate is compensated by a decreased angle $\theta$.

\section{Conclusions}

The utility of modern, recreational digital cameras, together with electronic file transfer and computer software for digital photograph processing, brings experimental determination of laminar burning velocities into the realm of undergraduate education. The intrinsic sensitivity of the burning velocities, though, to fuel/oxidant mixture composition requires the use of carefully calibrated gas flowmeters at a minimum. A reasonable precision can be obtained. Ammonia acts to slow methane/air flames.

\section{Acknowledgement}

The authors are grateful to the Center for Environmental Engineering and Science (CEES) at the New Jersey Institute of Technology (NJIT) for its support of this work, especially the purchase of the digital camera. 


\section{References}

1. Fristrom, R. M., Flame Structure and Processes, Oxford University Press: New York (1995).

2. Lewis, B. \& von Elbe, G., Combustion, Flames, and Explosions of Gases, Academic Press: New York (1987).

3. Gibbs, G. J. and Calcote, H. F., Journal of Chemical and Engineering Data 4(3), (1959).

4. Glassman, I., Combustion, Second Edition, Academic Press: New York (1987).

5. Barat, R., Chemical Engineering Science 56, pp. 2761-2766 (2001).

6. Reaction Design, Inc. - www.reactiondesign.com

7. Singer, J. M., Fourth Symposium (Int.) on Combustion, The Combustion Institute: Pittsburgh, PA, 352-358 (1953).

Table 1: Dependence of Measured LBV on Cold Gas Velocity at Constant $\phi$ and $\mathrm{r}$ Feed: $\mathrm{CH}_{4}, \mathrm{NH}_{3}$, air at $\phi=1.25, \mathrm{r}=0.15$

$\begin{array}{ll}\bar{u}_{g}(\mathrm{~cm} / \mathrm{s}) & \mathrm{S}_{\mathrm{u}}(\mathrm{cm} / \mathrm{s}) \\ 175 & 26.5 \\ 151 & 28.2 \\ 138 & 28.0 \\ 126 & 27.5 \\ 114 & 26.8\end{array}$




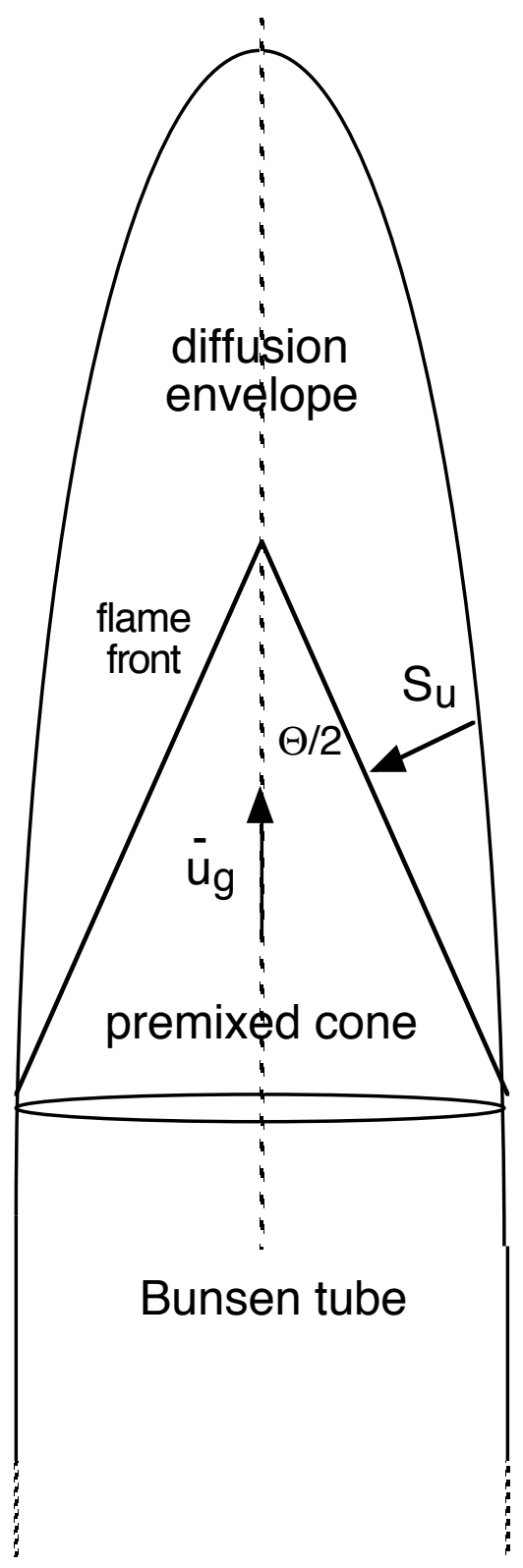

FIGURE 1: Simplified schematic of the Bunsen flame cone 


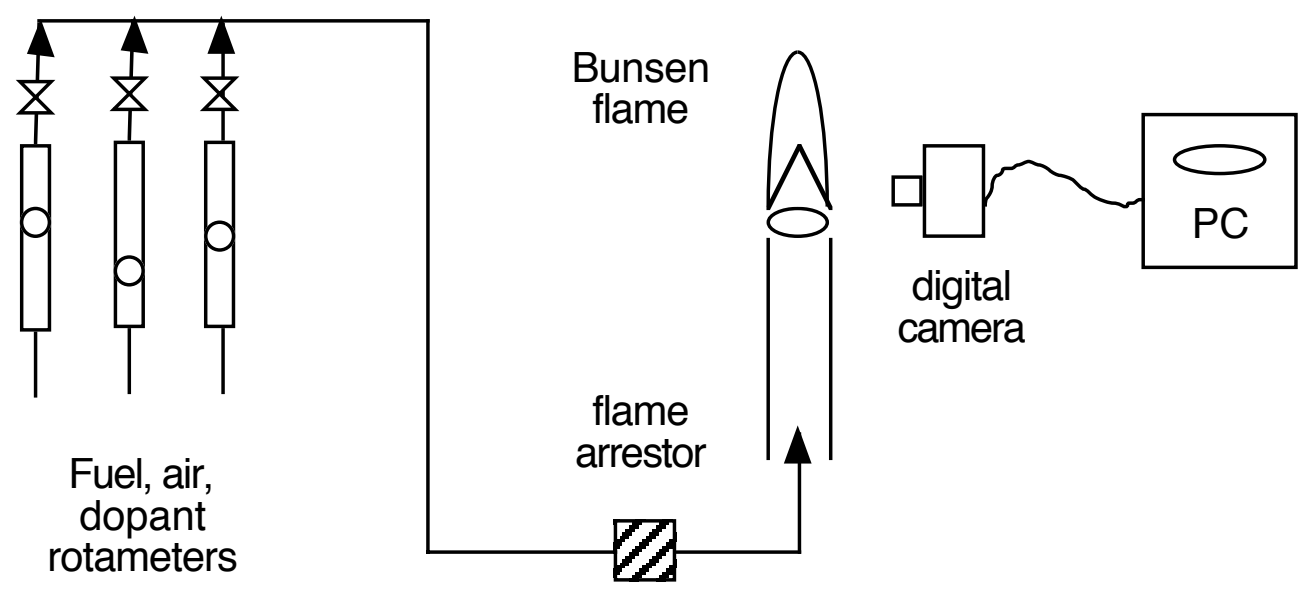

FIGURE 2: Experimental layout for burning velocity study 


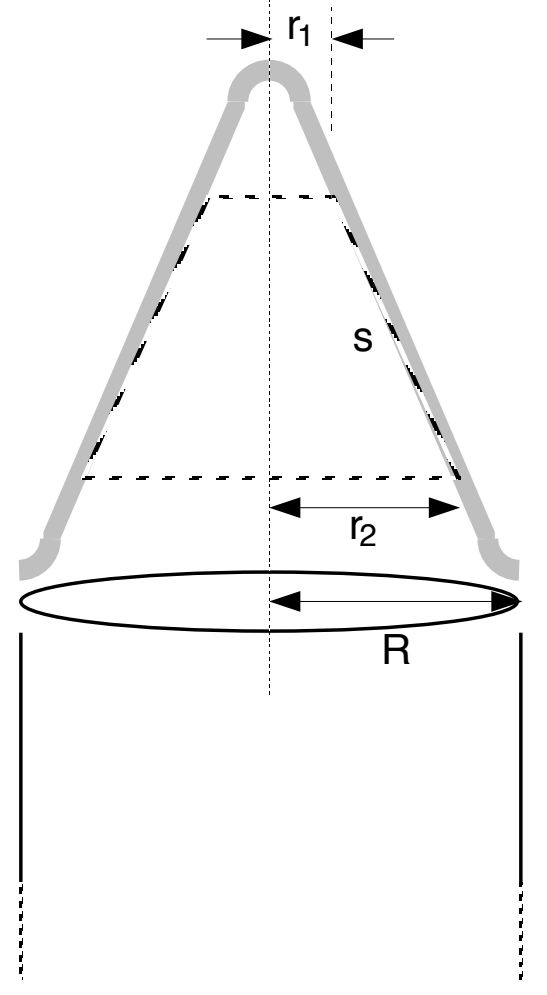

FIGURE 3: Enhanced detail of Bunsen cone showing frustrum 


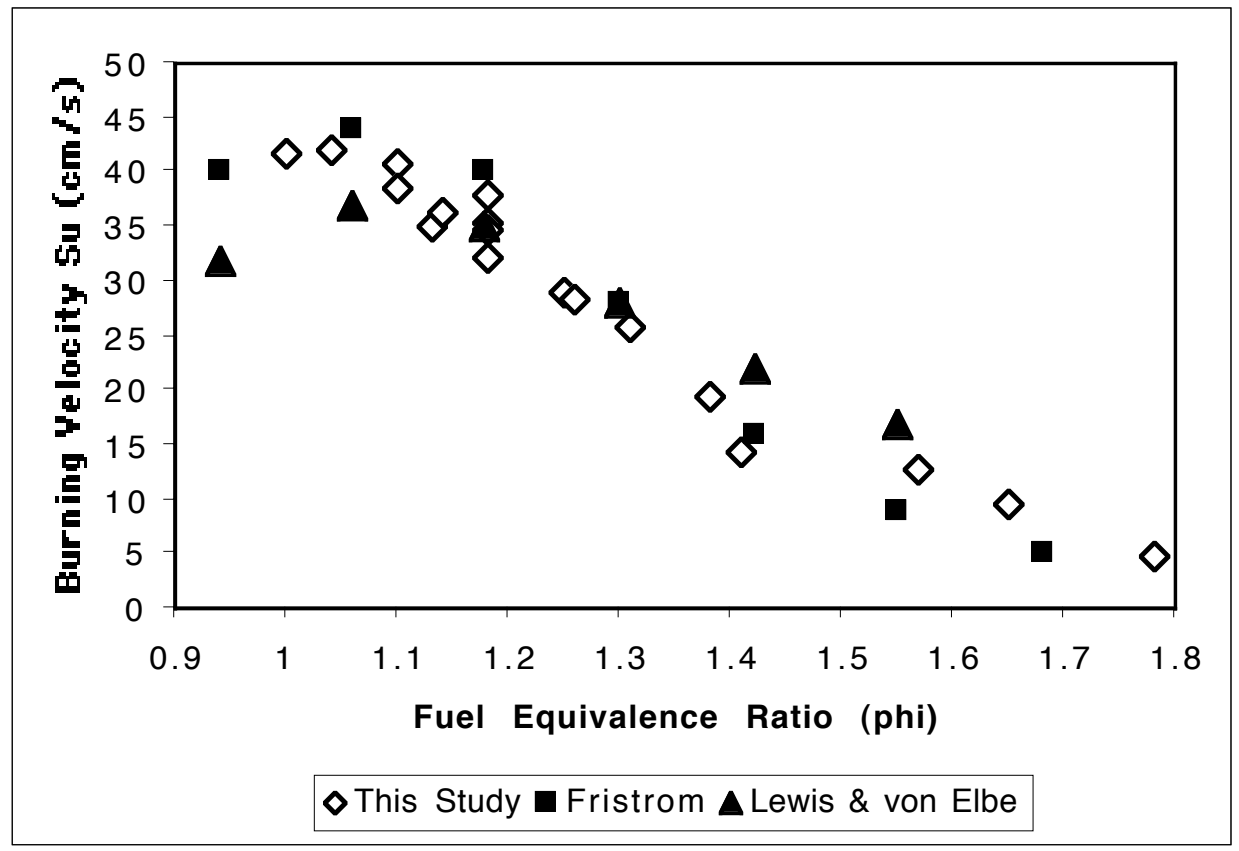

FIGURE 4: Laminar burning velocities for fuel-rich methane/air flames 


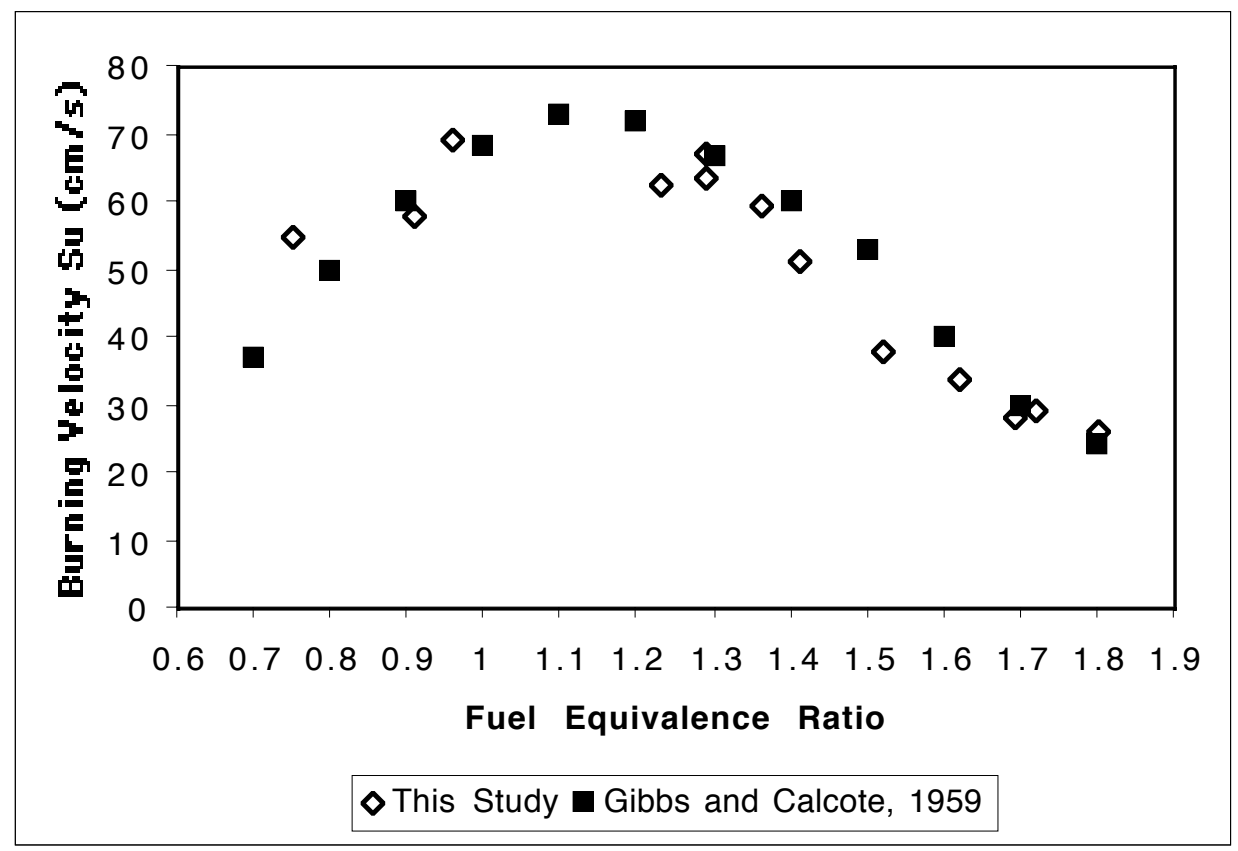

FIGURE 5: Laminar burning velocities for fuel-rich ethylene/air flames 


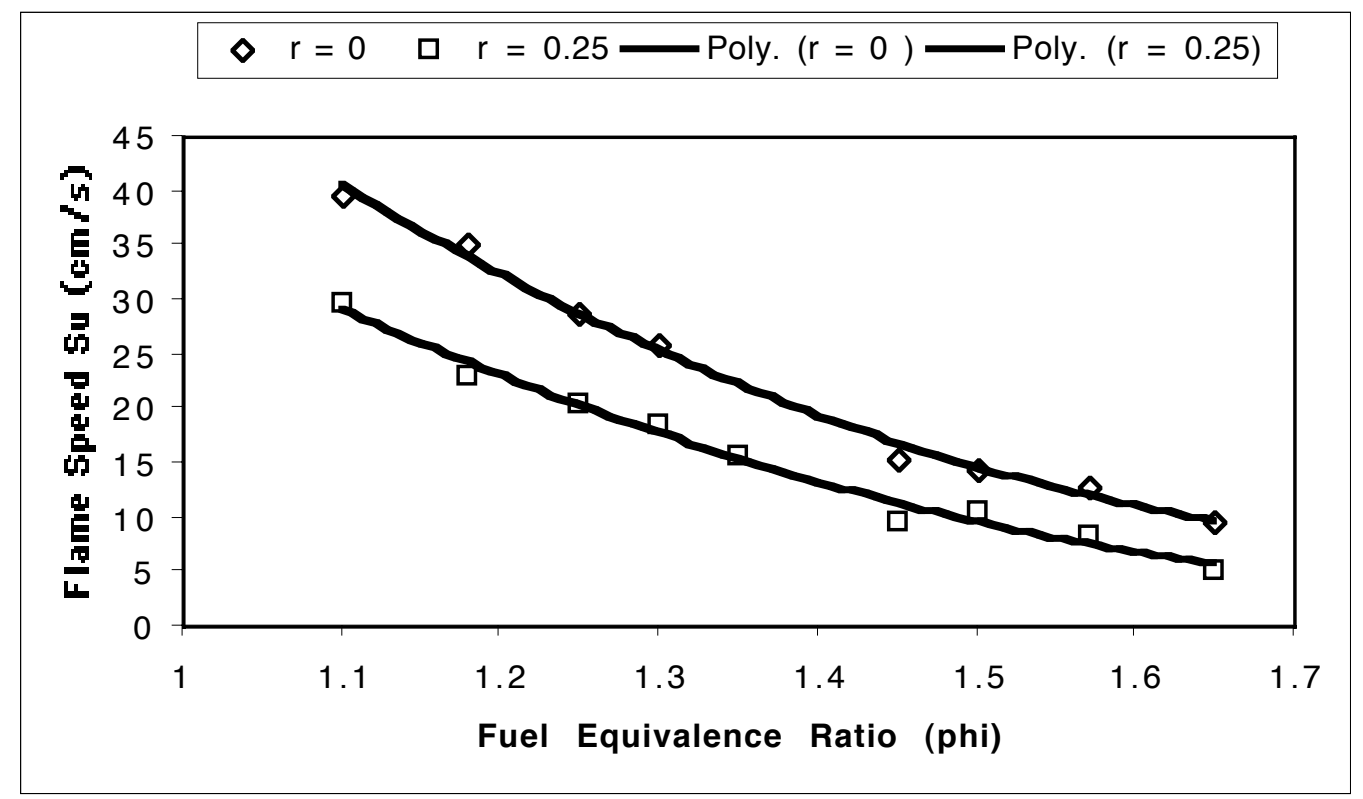

FIGURE 6: Impact of ammonia doping of fuel-rich methane/air flames 